\title{
Inmunosupresores no biológicos en dermatología
}

Nonbiological immunosuppressants in dermatology

\author{
Katherine Santacoloma1, Alberto José Maestre', Lili Rueda², Adriana Motta² \\ 1. Médico, residente del programa de Dermatología, Universidad El Bosque, Bogotá, D.C., Colombia \\ 2. Dermatóloga y epidemióloga clínica; docente, programa de Dermatología, Universidad El Bosque, Bogotá, D.C., Colombia
}

\section{RESUMEN}

La terapia inmunosupresora no biológica es de uso frecuente en la práctica dermatológica diaria en un amplio número de dermatosis inflamatorias. Su uso debe basarse en el entendimiento de su farmacología -mecanismo de acción, farmacocinética y efectos secundarios- que le permita al dermatólogo hacer un seguimiento adecuado, y la tamización y la profilaxis oportunas antes de su uso.

PALABRAS CLAVE: inmunosupresores, farmacología, farmacocinética, tamización

\section{SUMMARY}

Nonbiological immunosuppressive therapy is frequently used in dermatological daily practice in a large number of inflammatory dermatoses. Its use should be based on the understanding of its pharmacology: mechanism of action, pharmacokinetics and adverse effects, allowing the dermatologist to realize adequate monitoring and opportune screening and prophylaxis prior to its use.

KEY WORDS: immunosuppressive agents, pharmacology, pharmacokinetics, diagnosis

\section{INTRODUCCIÓN}

Los medicamentos inmunosupresores no biológicos se han empleado por varios años en el tratamiento de diversas enfermedades; estos fármacos son agentes capaces de ejercer una acción inhibitoria sobre el funcionamiento del sistema inmunológico.

En la práctica de la dermatología, estos medicamentos son usualmente requeridos para el tratamiento de dermatosis inflamatorias graves o resistentes a fármacos tópicos. Los corticosteroides orales se consideran antiinflamatorios sistémicos de primera línea; sin embargo, frecuentemente, se necesitan otros inmunomoduladores para controlar la actividad de la enfermedad y, a la vez, disminuir la dosis o eliminar el uso de corticosteroides, ya que estos tienen importantes efectos secundarios a largo plazo.
Correspondencia:

Katherine Santacoloma

Email:

ksantacoloma@hotmail.com

Recibido: 13/08/2016

Aceptado: 27/03/2017

Conflictos de interés:

No se reportan conflictos de interés.

Financiación:

Ninguna. 
Dada la importancia de estos medicamentos en dermatología, se revisan el mecanismo de acción, los aspectos farmacocinéticos, los efectos secundarios y el seguimiento durante su uso; además, las medidas previas de tamización y profilaxis.

\section{INMUNOSUPRESORES}

Los inmunosupresores pueden agruparse en dos grandes categorías: los no esteroideos o no biológicos, y los productos inmunobiológicos. Los fármacos no esteroideos, o no biológicos, más comunes son: azatioprina, ciclofosfamida, ciclosporina, metrotexato, antipalúdicos y micofenolato de mofetilo ${ }^{1}$. Los productos inmunobiológicos, a diferencia de los fármacos ahorradores de esteroides, son moléculas de proteínas producidas mediante tecnología de ADN recombinante, las cuales se dirigen a los sitios específicos en la vía inmunopatogénica de las enfermedades ${ }^{2}$.

Los productos biológicos se dividen en tres grupos: anticuerpos monoclonales, proteínas de fusión y citocinas humanas recombinantes-factores de crecimiento. Debido a su acción específica en el sistema inmunológico, se considera su perfil de seguridad es más favorable en comparación con el de los inmunosupresores tradicionales. No obstante, su efecto secundario más común son las infecciones de novo o la reactivación de infecciones latentes como la tuberculosis, por lo que requieren pruebas de tamización antes de su inicio. A pesar de su eficacia y seguridad, no se consideran medicamentos de primera línea por su alto costo ${ }^{3,4}$.

Los inmunosupresores no biológicos pueden ser esteroideos o no esteroideos. Estos últimos se clasifican según su mecanismo de acción: inhibidores de la calcineurina (ciclosporina, tacrolimus), agentes citotóxicos (metotrexato, azatioprina, micofenolato de mofetilo, ciclofosfamida), inhibidores de mTOR (mammalian Target of Rapamycin) como sirolimus y everolimus, y otros agentes inmunomoduladores y antiinflamatorios (antibióticos, antipalúdicos, talidomida, inmunoglobulinas) (figura 1) ${ }^{1}$.

Estos medicamentos se consideran una herramienta de formulación cotidiana en la dermatología, ya que son útiles en el tratamiento de enfermedades autoinmunitarias de expresión cutánea y de enfermedades inflamatorias cutáneas crónicas (tabla 1). Todos tienen efectos indeseables en común, relacionados con su grupo terapéutico y con su acción sobre el sistema inmunológico, que aumentan el riesgo de infecciones oportunistas y neoplasias, ya que reprimen el sistema de inmunovigilancia tumoral y algunas moléculas tienen un potencial carcinogénico agregado 5,6 .

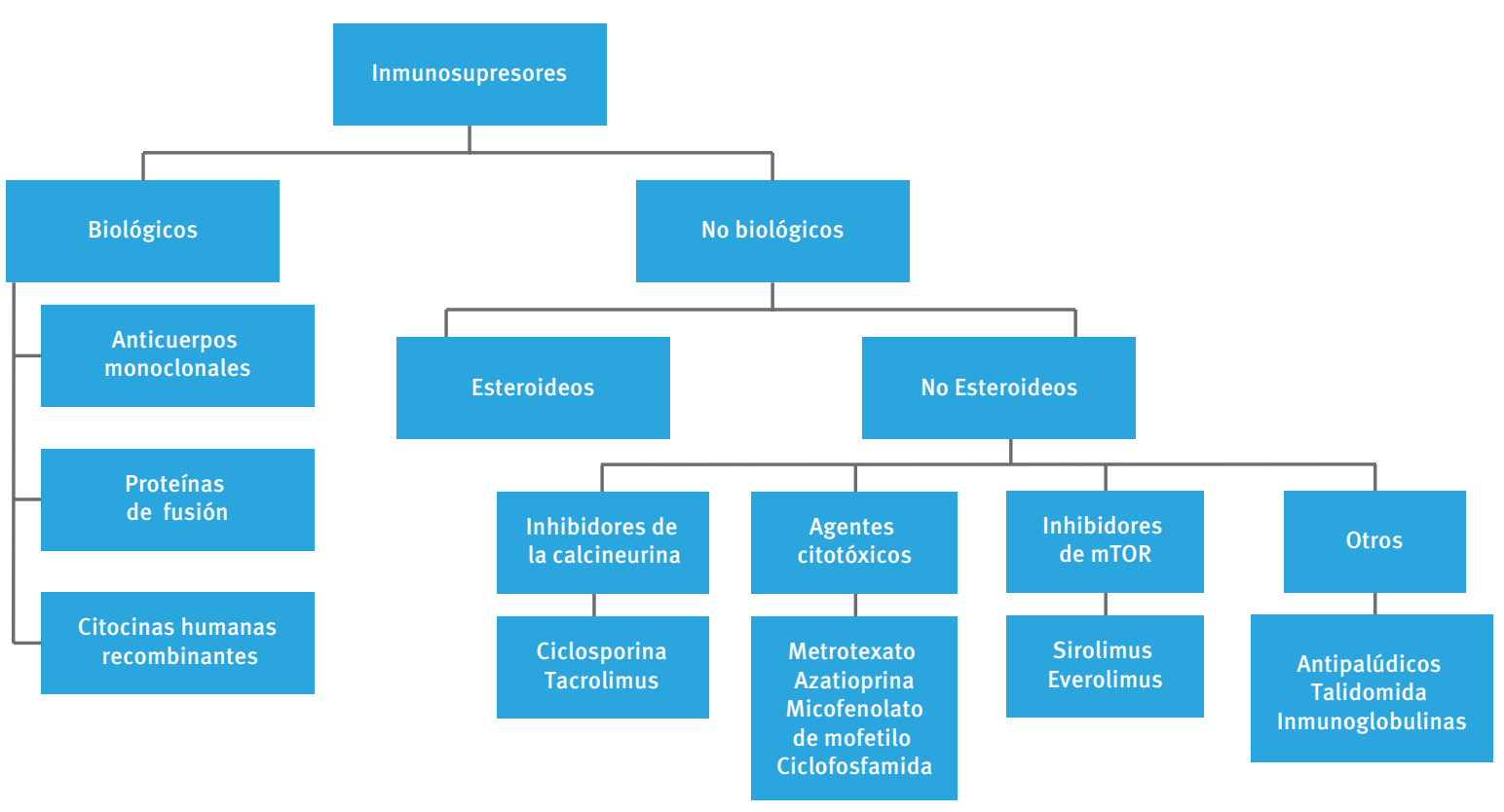

Figura 1. Clasificación de los inmunosupresores 


\section{ENFERMEDADES DERMATOLÓGICAS QUE REQUIEREN TERAPIA INMUNOSUPRESORA NO BIOLÓGICA,}

\begin{tabular}{|c|c|}
\hline Enfermedades ampollosas & Pénfigo, penfigoide ampolloso, epidermólisis ampollosa \\
\hline Enfermedades del colágeno & $\begin{array}{l}\text { Lupus eritematoso cutáneo, lupus eritematoso sistémico, dermatomiositis, } \\
\text { esclerodermia }\end{array}$ \\
\hline Enfermedades eccematosas & Dermatitis atópica, dermatitis de contacto, dermatitis actínica \\
\hline Vasculitis & $\begin{array}{l}\text { Vasculitis leucocitoclásticas, fenómeno de Raynaud, enfermedad de Behçet, } \\
\text { granulomatosis de Wegener }\end{array}$ \\
\hline Psoriasis & Psoriasis severa \\
\hline Enfermedades varias & $\begin{array}{l}\text { Liquen plano, pioderma gangrenoso, pitiriasis liquenoide y varioliforme aguda } \\
\text { (PLEVA), papulosis linfomatoide, pitiriasis rubra pilaris, sarcoidosis }\end{array}$ \\
\hline
\end{tabular}

Tabla 1. Enfermedades dermatológicas que requieren terapia inmunosupresora no biológica $^{1,2}$

Por lo tanto, es muy importante conocer su farmacología, modo de acción y efectos secundarios. A continuación se revisan los agentes sistémicos más frecuentemente usados en dermatología, primero los corticosteroides sistémicos y después los inmunosupresores no esteroideos.

\section{CORTICOSTEROIDES SISTÉMICOS}

Los corticosteroides son análogos sintéticos de las hormonas esteroideas producidas por la corteza suprarrenal, y son una opción importante en la práctica de la dermatología para tratar una gran variedad de enfermedades de la piel. Son muy efectivos para lograr un rápido control de las dermatosis agudas graves y son útiles como tratamiento de primera línea o como terapia adyuvante para varias enfermedades inflamatorias crónicas ${ }^{7-9}$.

Su mecanismo de acción consiste en la unión del corticosteroide al receptor de glucocorticoides localizado en el citoplasma de casi todas las células del cuerpo, con posterior translocación nuclear de este complejo de unión. En el núcleo, el receptor de glucocorticoides forma un dímero que se une al elemento de reacción a los glucocorticoides de la región promotora de los genes sensibles a los esteroides. Esta unión altera la tasa de transcripción, reprimiendo o induciendo la producción de ARN mensajero y la síntesis de proteínas ${ }^{7}$.

El receptor de glucocorticoides también interactúa con otros factores de transcripción que tienen un papel central en la reacción inflamatoria. Al inhibir el factor AP-1 y el factor nuclear Қ $\mathrm{B}$, dos importantes factores de transcripción que tienen una función significativa en la inflamación crónica, los glucocorticoides pueden disminuir la transcripción de genes de diversas citocinas, moléculas de adhesión, enzimas inflamatorias y factores de crecimiento. Igualmente, inhiben el factor de necrosis tumoral $\alpha$, el factor estimulante de colonias de granulocitos y macrófagos, y varias interleucinas (IL-1, IL-2, IL-6 e IL-8). De esta manera, producen sus efectos antiinflamatorios, inmunosupresores, antiproliferativos y vasoconstrictores ${ }^{7-9}$.

Todos los corticosteroides tienen una estructura básica de cuatro anillos de colesterol, tres anillos de hexano y un anillo pentano. Las modificaciones en la estructura de cuatro anillos resultan en agentes que varían en potencia, efecto mineralocorticoide, vida media y metabolismo. El corticosteroide biológicamente activo tiene un grupo hidroxilo en la posición ${ }^{11}$, que proviene de un grupo cetona en el hígado. La prednisona, por ejemplo, debe someterse a hidroxilación en el hígado para producir el agente activo prednisolona. Por lo tanto, en pacientes con enfermedad hepática, es mejor utilizar un agente activo como tal ${ }^{7}$.

Los corticosteroides orales se absorben en el yeyuno y presentan un pico plasmático entre los $30 \mathrm{y}$ los $90 \mathrm{mi}$ nutos. Tiene una vida media que varía de una a cinco horas, pero la duración de su efecto se mide con el periodo de supresión de secreción de la hormona adrenocorticotropa (ACTH) por la glándula pituitaria después de su administración. Los corticosteroides de corta ac- 
ción tienen efecto entre 8 y 12 horas; los de acción intermedia, de 24 a 36 horas, y los de larga acción, de más de 48 horas $^{7,8}$.

Algunos corticosteroides tienen una actividad mineralocorticoide significativa; pueden actuar en el riñón y promover la reabsorción activa de sodio y la reabsorción pasiva de agua, regulando el equilibrio hidroelectrolítico. La hidrocortisona tiene una importante potencia mineralocorticoide, la prednisona y la prednisolona tienen ligeros efectos, mientras que la metilprednisolona no tiene actividad mineralocorticoide, por lo que esta sería una excelente opción en situaciones en las cuales hay que evitar estos efectos (tabla 2) ${ }^{7-9}$.

Existen diferentes opciones en cuanto a las dosis y las vías de administración de los corticosteroides sistémicos, que incluyen terapia oral a corto plazo, terapia oral a largo plazo con titulación eventual, preparaciones intramusculares de corta y larga acción, y administración intravenosa diaria o en pulsos a altas dosis. El efecto inmunosupresor de los corticosteroides depende de la dosis y del tiempo de administración, y se produce con más de $20 \mathrm{mg}$ diarios durante más de dos semanas. En dermatología, la dosis diaria de prednisona usualmente requerida es de 0,5 a $3 \mathrm{mg} / \mathrm{kg}{ }^{7}$.

Los agentes ahorradores de corticosteroides se añaden al esquema terapéutico para disminuir la dosis de corticoides requerida para controlar la enfermedad o para suspenderlo, ya que los corticoides pueden generar mu- chos efectos secundarios, especialmente si se administran durante un tiempo prolongado. Entre sus efectos secundarios están las alteraciones musculoesqueléticas, oftalmológicas, gastrointestinales, metabólicas, cardiovasculares, ginecoobstétricas, hematológicas, cutáneas, las del eje hipotálamo-hipófiso-suprarrenal y las del sistema nervioso central (tabla 3) ${ }^{7-9}$.

Además, el efecto inmunosupresor de los corticosteroides aumenta la vulnerabilidad de los pacientes ante infecciones por bacterias, virus, hongos y parásitos, y su diagnóstico puede ser difícil debido a la incapacidad de estos individuos de generar una reacción inflamatoria normal. Antes de iniciar el tratamiento, muchos médicos sugieren evaluar la presencia de tuberculosis con una radiografía de tórax y, cuando la prueba de tuberculina sea positiva o exista el antecedente de tuberculosis, administrar isoniacida ${ }^{8}$.

Siempre se deben tener en cuenta las contraindicaciones de estos fármacos, como son las infecciones fúngicas sistémicas y la historia de hipersensibilidad al medicamento. Otras contraindicaciones relativas son la úlcera péptica activa, tuberculosis activa, depresión grave $\mathrm{u}$ otras psicosis, y las dermatosis reactivas extensas (por ejemplo, psoriasis) propensas a reactivarse después de una disminución rápida de la dosis de corticosteroides 7,9 .

\section{CORTICOSTEROIDES Y SU FARMACOLOGİA}

\section{COMPUESTO}

Dosis

glucocorticosteroide equivalente (mg)
Actividad

glucocorticoide

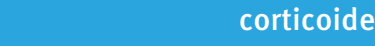

Duración

de acción

(horas)
Vía de

administración

\section{ACCIÓN CORTA}

Cortisona

Hidrocortisona

\begin{abstract}
25
\end{abstract}
20
1

0.8
$8-12$

$8-12$ vía oral intramuscular, intravenosa

ACCIÓN INTERMEDIA

\begin{tabular}{llllll} 
Prednisona & 5 & 4 & 0.8 & $24-36$ & vía oral \\
Prednisolona & 5 & 4 & 0.8 & $24-36$ & vía oral \\
Metilprednisolona & 4 & 5 & 0 & $24-36$ & intramuscular, intravenosa \\
\hline Triamcinolona & 4 & 5 & 0 & $24-36$ & intramuscular \\
\hline ACCIÓN LARGA & & & & & intramuscular, intravenosa \\
Dexametasona & 0.60 & 30 & 0 & $36-72$ & intramuscular \\
Betametasona & 0.75 & 30 & 0 & $36-72$ &
\end{tabular}

Tabla 2. Corticosteroides y su farmacología ${ }^{8,9}$ 


\begin{tabular}{|c|c|}
\hline \multicolumn{2}{|c|}{ EFECTOS SECUNDARIOS A LARGO PLAZO DE LA TERAPIA CORTICOSTEROIDE } \\
\hline Músculo-esqueléticos & $\begin{array}{l}\text { Osteoporosis, osteonecrosis, retardo del crecimiento, atrofia } \\
\text { muscular, miopatía }\end{array}$ \\
\hline Oftalmológicos & Cataratas, glaucoma, infección, hemorragia, exoftalmos \\
\hline Gastrointestinales & Náuseas, vómitos, úlcera péptica, pancreatitis, esofagitis \\
\hline Metabólicos & $\begin{array}{l}\text { Hiperglucemia, hiperlipidemia, obesidad, hipocalcemia, alcalosis } \\
\text { hipopotasémica }\end{array}$ \\
\hline Cardiovasculares & Hipertensión, edema, ateroesclerosis \\
\hline Ginecobstétricos & Amenorrea, efectos fetales \\
\hline $\begin{array}{l}\text { Eje hipófisis - } \\
\text { hipotálamo- adrenal }\end{array}$ & Supresión, síndrome de abstinencia, crisis suprarrenal \\
\hline Hematológicos & $\begin{array}{l}\text { Leucocitosis, linfopenia, eosinopenia, inmunosupresión, disminu- } \\
\text { ción de tasa mitótica, infecciones }\end{array}$ \\
\hline Sistema Nervioso & $\begin{array}{l}\text { Cambios en la personalidad o en el ánimo, problemas psiquiátricos, } \\
\text { psicosis, convulsiones, pseudotumor cerebri, neuropatía periférica }\end{array}$ \\
\hline Cutáneos & $\begin{array}{l}\text { Atrofia, efectos vasculares, púrpura, hirsutismo, hiperpigmentación, } \\
\text { acné, erupciones acneiformes, infecciones }\end{array}$ \\
\hline
\end{tabular}

Tabla 3. Efectos secundarios a largo plazo de la terapia corticosteroide ${ }^{7}$

\section{METOTREXATO}

El metrotexato es el inmunosupresor no esteroideo más comúnmente usado en dermatología, con una eficacia conocida para muchas enfermedades de la piel y con varios años de experiencia en su perfil de seguridad. Es un antimetabolito análogo del ácido fólico que inhibe potentemente y de manera irreversible a la dihidrofolato-reductasa intracelular, enzima responsable de la conversión del dihidrofolato a tetrahidrofolato. El tetrahidrofolato es un cofactor necesario para varias enzimas involucradas en la síntesis de purinas y pirimidinas, las cuales se requieren para la síntesis de ADN y ARN. Por lo tanto, el medicamento tiene un efecto específico sobre la fase $S$, al inhibir la división celular y bloquear la proliferación y las funciones de los linfocitos $\mathrm{T}$ y $\mathrm{B}$, al igual que la proliferación de los monocitos y queratinocitos ${ }^{1,10}$. El metotrexato presenta una concentración plasmática máxima una o dos horas después de su administración y su vida media es de 6 a 7 horas. Aproximadamente, del 35 al $50 \%$ se une de manera no covalente a la albúmina y del 50 al $90 \%$ se elimina por el riñón en 24 horas. El metrotexato se prescribe habitualmente por vía oral, pero también se puede administrar de manera subcutánea, intramuscular o intravenosa. Para los trastornos inflamatorios, se usan casi exclusivamente dosis orales o intramusculares de 7,5 a $30 \mathrm{mg}$ por semana, y su presentación es en tabletas de 2,5 mg o en ampollas de $25 \mathrm{mg} / \mathrm{ml}$. La administración parenteral se recomienda cuando produce intolerancia gástrica ${ }^{2,10,11}$.

Este antifólico tiene como principal indicación la psoriasis grave o resistente, y está contraindicado en insuficiencia renal (depuración de creatinina menor de $40 \mathrm{ml}$ por minuto), insuficiencia hepática significativa, hepatitis, cirrosis, alcoholismo, obesidad, diabetes mellitus y anemia, leucopenia o trombocitopenia graves; también, en pacientes inmunodeprimidos y en mujeres embarazadas o durante la lactancia, puesto que es teratógeno y abortivo. Debe retrasarse la concepción hasta tres meses después de haberse suspendido el medicamento ${ }^{1,10,11}$. 
Entre sus efectos secundarios se encuentran: afectación mielotóxica (leucopenia o trombocitopenia), fibrosis hepática, toxicidad pulmonar expresada como neumopatía por hipersensibilidad o fibrosis intersticial difusa, y trastornos mucosos y gastrointestinales; además, produce un mayor riesgo de carcinoma escamocelular en pacientes con psoriasis (riesgo relativo de 2,1) y, menos frecuentemente, trastornos linfoproliferativos inducidos por el virus de Epstein-Barr. Es importante el suplemento de ácido fólico, ya que se ha demostrado que reduce los efectos secundarios gastrointestinales y hematológicos y la hepatotoxicidad, sin alterar su eficacia ${ }^{1,2,11,12}$.

\section{AZATIOPRINA}

La azatioprina tiene propiedades antileucémicas, antiinflamatorias e inmunosupresoras, por lo cual se usa en diferentes especialidades. En dermatología, se utiliza como inmunosupresor y agente ahorrador de esteroides para tratar enfermedades autoinmunitarias e inflamatorias de la piel. Es un profármaco análogo sintético de las purinas. Su metabolismo se lleva a cabo en el hígado y su mecanismo de acción se produce por medio de tres vías enzimáticas: la de la tiopurina-metiltransferasa (TPMT), que causa metilación de la azatioprina (AZT) en 6-mercaptopurina (6-MP); la de la xantina oxidasa, que oxida la 6-MP en ácido 6-tioúrico; y la de la hipoxantinaguanina fosforribosiltransferasa, la cual convierte la 6-MP en metabolitos de la 6-tioguanina. Estos metabolitos inhiben la síntesis de las purinas que forman los ácidos nucleicos, lo cual resulta en inhibición de la proliferación de los linfocitos T y $\mathrm{B}^{1,13-16}$.

Con respecto a su farmacocinética, la absorción por vía oral es rápida, alcanza una concentración plasmática máxima en dos horas y su vida media es de tres horas. El 30 \% del medicamento se une a las proteínas plasmáticas. La AZT y sus metabolitos pueden atravesar la barrera placentaria y encontrarse en la leche materna. Se elimina por la orina en forma de metabolitos inactivos. Su presentación es en tabletas de $50 \mathrm{mg}$ y la dosis inicial es de 1 a $2 \mathrm{mg} / \mathrm{kg}$ por día en una o dos dosis; después de 6 a 8 semanas, se puede aumentar 0,5 mg/ $\mathrm{kg}$ cada cuatro semanas, hasta un máximo de $3 \mathrm{mg} / \mathrm{kg}$ por día. Si no se observa mejoría en 12 a 16 semanas, se debe descontinuar ${ }^{1,2,5,14}$.

Inicialmente, este medicamento fue usado como inmunosupresor en casos de trasplante renal; actualmente, es uno de los inmunomoduladores más utilizados en dermatología, y sus indicaciones más comunes son las enfermedades ampollosas, la dermatitis atópica y la dermatomiositis. Su principal contraindicación es la hi- persensibilidad a la molécula; igualmente, está contraindicada durante la lactancia materna. Los efectos indeseables más frecuentes son mielotoxicidad (citopenias, macrocitosis, megaloblastosis, hipoplasia medular), manifestaciones gastrointestinales (náuseas, diarrea), manifestaciones hepáticas (colestasis, alteración de la función hepática) y mayor riesgo de carcinogénesis (carcinoma escamocelular y trastornos linfoproliferativos) $)^{1,2,6,14,17}$.

\section{MICOFENOLATO DE MOFETILO}

El micofenolato de mofetilo es un inmunosupresor relativamente nuevo cuyo uso se ha incrementado en dermatología. Ha mostrado eficacia en varias enfermedades inflamatorias de la piel y un perfil de seguridad favorable en el campo de los trasplantes de órganos, ya que no presenta toxicidad hepática ni renal. No obstante, su uso se ha limitado en dermatología por la falta de estudios controlados de asignación aleatoria y por su alto costo. Este medicamento es un profármaco del ácido micofenólico, el cual es un ácido débil formado durante la fermentación de diferentes especies de Penicillium. Tiene propiedades antifúngicas, antibacterianas y antivirales, al igual que antitumorales e inmunosupresoras ${ }^{18,19}$.

El micofenolato de mofetilo es un éster del ácido micofenólico que es convertido en ácido micofenólico por estereasas en el plasma, el hígado y el riñón. Después, el ácido micofenólico es inactivado en el hígado mediante glucuronidación y una porción se recicla en la circulación enterohepática donde es activado por la enzima $\beta$-glucuronidasa, ubicada en el tubo digestivo y la epidermis. El ácido micofenólico activo inhibe la inosina-monofosfato-deshidrogenasa de tipo 2, enzima requerida para la síntesis de purinas, lo cual resulta en una potente inhibición de las funciones linfocíticas $\mathrm{T}$ y $\mathrm{B}$, como la producción de anticuerpos y la formación de linfocitos T citotóxicos ${ }^{1,2,18-20}$.

Este medicamento tiene una biodisponibilidad oral del $94 \%$, pero puede disminuir en $40 \%$ en presencia de alimentos o de colestiramina. Su vida media es de 18 horas, con un pico secundario de concentración plasmática de las 6 a 12 horas debido a su ciclo enterohepático. El 93 \% se elimina por la orina en forma inactiva y, el $6 \%$, por las heces ${ }^{1,18,19}$.

Su principal indicación es para la profilaxis del rechazo de trasplante de órganos. En dermatología se ha usado en psoriasis, enfermedades ampollosas autoinmunitarias, dermatitis atópica y enfermedades del tejido conjuntivo, a dosis diarias de 2 a $3 \mathrm{~g}$ por vía oral. Aunque 
tiene un perfil favorable de tolerabilidad, está contraindicado en el embarazo, durante la lactancia materna y cuando hay hipersensibilidad al ácido micofenólico. Sus efectos secundarios son muy similares a los de la azatioprina, con alteraciones hematológicas y gastrointestinales ${ }^{2,19,20}$.

\section{ANTIPALÚDICOS}

Los antipalúdicos originalmente fueron desarrollados para el tratamiento de la malaria: no obstante, desde hace más de 50 años se han usado para tratar enfermedades de la piel, siendo el tratamiento de elección para las manifestaciones cutáneas del lupus eritematoso, por su gran efectividad y sus efectos adversos tolerables ${ }^{21,22}$. Los antipalúdicos sintéticos quinacrina, cloroquina e hidroxicloroquina son derivados de la quinina, alcaloide natural aislado de la corteza del quino, un árbol originario de Suramérica. La quinina fue el primer antipalúdico natural que protegió del paludismo a los colonos europeos que llegaron a los países tropicales ${ }^{21,22}$.

El mecanismo de acción de estos medicamentos no se conoce por completo, pero tienen acción inmunomoduladora, antiinflamatoria, antiproliferativa y fotoprotectora. Se acumulan dentro de los lisosomas, aumentándoles el pH, por lo que interfieren en la unión de los antígenos con las moléculas del complejo mayor de histocompatibilidad (CMH) de tipo II. Por lo tanto, evitan su presentación a los linfocitos T CD4, inhibiendo la producción de citocinas involucradas en el origen de la reacción inflamatoria. Igualmente, inhiben la señalización del receptor endosómico de tipo toll, limitando la activación de los linfocitos B y las células dendríticas ${ }^{21,22}$. La cloroquina y la hidroxicloroquina son 4-aminoquinolinas, las cuales se diferencian por un grupo hidroxilo que tiene la hidroxicloroquina. Después de su administración oral, alcanzan un pico de concentración plasmática a las 8-12 horas, y su vida media es de 74 horas a 50 días, dependiendo de la dosis acumulada. Alcanzan concentraciones estables de las 4 a las 6 semanas, por lo que se requiere como mínimo este tiempo para obtener una acción terapéutica. Se unen en 60 \% a las proteínas plasmáticas y se depositan en los tejidos (hígado, bazo, riñones y pulmón). La mayor concentración de estos medicamentos se encuentra en las células de la retina y la piel que contienen melanina, la cual es entre 100 y 200 veces mayor que en el plasma, lo cual da lugar a un gran riesgo de toxicidad ocular, más frecuente con la cloroquina. Se eliminan por la orina en el 45 al $50 \%$. Ambos fármacos atraviesan la placenta y son excretados en la leche materna.
Se administran por vía oral, en dosis de $250 \mathrm{mg}$ diarios $(3,5 \mathrm{mg} / \mathrm{kg})$ la cloroquina, y de $400 \mathrm{mg}$ diarios $(6,5 \mathrm{mg} /$ $\mathrm{kg}$ ), la hidroxicloroquina ${ }^{21-23}$.

La quinacrina es una 9-aminocridina con una farmacocinética muy similar a la de las dos anteriores; difiere en su estructura por un núcleo de acridina que contiene un anillo extra de benceno. Fue el primer antipalúdico sintético. Se emplea poco porque no hay suficiente información sobre su uso y por falta de comercialización en todos los países. Sin embargo, es eficaz como monoterapia y en combinación con otros antipalúdicos en casos resistentes, pues potencia la acción de la cloroquina y la hidroxicloroquina. Además, al parecer, carece de toxicidad retiniana, por lo que se utiliza cuando hay alteraciones oculares previas que contraindican el uso de las cloroquinas ${ }^{23,24}$.

Entre otros, los antipalúdicos pueden causar varios efectos secundarios oculares que son reversibles; no obstante, el más temido es la retinopatía, la cual puede generar déficit irreversible de la visión y su aparición obliga a suspender el tratamiento. También pueden originar efectos secundarios gastrointestinales (náuseas, vómito y diarrea), cutáneos (pigmentación grisazulada, blanqueamiento de la raíz del pelo y bandas transversales en las uñas), neuromusculares y, menos frecuentes, cardiacos y hematológicos. Están contraindicados cuando existe retinopatía previa o hipersensibilidad conocida, y en pacientes que reciban tratamiento inmunosupresor de la médula ósea ${ }^{22,23}$.

\section{CICLOSPORINA}

La ciclosporina fue usada por primera vez para prevenir el rechazo del trasplante de órganos sólidos. Se utiliza en dermatología para la psoriasis, principalmente, y también en otras dermatosis inflamatorias como la dermatitis atópica, las enfermedades ampollosas y las enfermedades del tejido conjuntivo. Es un polipéptido cíclico, lipofílico, producido por el hongo Beauveria nivea, que bloquea las vías de transducción intracelular esenciales para los linfocitos, al inhibir la actividad de la fosfatasa de la calcineurina. Como resultado, la calcineurina es incapaz de desfosforilar el factor nuclear de los linfocitos T activados (Nuclear Factor of Activated T-cells, NFAT), por lo cual se inhibe la traslocación nuclear y se evita la transcripción de genes que codifican citocinas como la interleucina ${ }^{2}$, el interferón gamma y el factor estimulante de colonias de granulocitos y macrófagos, necesarios para la activación completa de la vía de las células T. Aunque la ciclosporina actúa sobre las líneas linfocíticas T y B, su acción se dirige principalmente a la 


\begin{tabular}{|c|c|c|}
\hline \multicolumn{3}{|c|}{ USOS DERMATOLÓGICOS DE INMUNOSUPRESORES NO BIOLÓGICOS } \\
\hline & Primera línea & Otras \\
\hline Corticosteroides $_{5,7,8}$ & $\begin{array}{l}\text { Enfermedades ampollosas } \\
\text { autoinmunes, enfermedades del } \\
\text { colágeno, enfermedades eccemato- } \\
\text { sas, vasculitis, dermatosis } \\
\text { neutrofílicas, reacciones medica- } \\
\text { mentosas, sarcoidosis }\end{array}$ & \\
\hline Metrotexato ${ }_{5,10}$ & $\begin{array}{l}\text { Psoriasis grave (extensión }>20 \% \\
\text { superficie corporal, eritrodérmica, } \\
\text { palmo-plantar, artritis psoriásica) }\end{array}$ & $\begin{array}{l}\text { Penfigoide ampolloso, dermatomio- } \\
\text { sitis, lupus eritematoso cutáneo o } \\
\text { sistémico, esclerodermia localiza- } \\
\text { da, dermatitis atópica grave, } \\
\text { vasculitis leucocitoclástica, }\end{array}$ \\
\hline Azatioprina ${ }_{5,13,14}$ & $\begin{array}{l}\text { Pénfigos, penfigoide ampolloso, } \\
\text { epidermólisis ampollosa adquirida, } \\
\text { lupus eritematoso cutáneo o } \\
\text { sistémico, dermatomiositis, } \\
\text { dermatitis atópica grave, dermatitis } \\
\text { actínica, vasculitis leucocitoclás- } \\
\text { tica, enfermedad de Behçet }\end{array}$ & \\
\hline 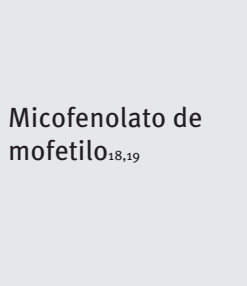 & & $\begin{array}{l}\text { Pénfigos, penfigoide ampolloso, } \\
\text { penfigoide cicatricial, epidermólisis } \\
\text { ampollosa adquirida, lupus } \\
\text { eritematoso, dermatomiositis, } \\
\text { esclerosis sistémica, dermatitis } \\
\text { atópica grave, dermatitis actínica, } \\
\text { vasculitides, enfermedad injerto } \\
\text { contra huésped }\end{array}$ \\
\hline Antipalúdicos 22 & $\begin{array}{l}\text { Lupus eritematoso sistémico y } \\
\text { cutáneo, porfiria cutánea tarda (sin } \\
\text { respuesta o contraindicación a } \\
\text { flebotomías) }\end{array}$ & $\begin{array}{l}\text { Dermatomiositis, sarcoidosis, } \\
\text { erupción polimorfa lumínica, } \\
\text { granuloma anular generalizado, } \\
\text { liquen plano pilar, alopecia frontal } \\
\text { fibrosante }\end{array}$ \\
\hline Ciclosporina $_{5,25,27}$ & $\begin{array}{l}\text { Psoriasis grave (eritrodérmica, } \\
\text { pustulosa), dermatitis atópica } \\
\text { grave, pioderma gangrenoso }\end{array}$ & $\begin{array}{l}\text { Penfigos, epidermólisis ampollosa } \\
\text { adquirida, eccema dishidrótico } \\
\text { grave, urticaria crónica, fotoderma- } \\
\text { tosis, dermatomiositis, enfermedad } \\
\text { de Behçet, granulomatosis de } \\
\text { Wegener, alopecia areata grave, } \\
\text { liquen plano, liquen plano pilar, } \\
\text { prúrigo nodulargranulomatosis de } \\
\text { Wegener }\end{array}$ \\
\hline Ciclofosfamida $a_{5,29}$ & $\begin{array}{l}\text { Penfigoide cicatricial, lupus } \\
\text { eritematoso sistémico, granuloma- } \\
\text { tosis de Wegener (granulomatosis } \\
\text { con poliangeítis) }\end{array}$ & $\begin{array}{l}\text { Pénfigos, penfigoide ampolloso, } \\
\text { epidermólisis ampollosa adquirida, } \\
\text { lupus eritematoso cutáneo, } \\
\text { dermatomiositis, esclerosis } \\
\text { sistémica, vasculitis leucocitoclás- } \\
\text { tica, micosis fungoide }\end{array}$ \\
\hline
\end{tabular}

Tabla 4. Usos dermatológicos de inmunosupresores no biológicos 
línea T y la inmunidad de mediación celular ${ }^{1,25-27}$.

Al ser una molécula lipofílica, este fármaco tiene una absorción variable, con una biodisponibilidad oral del $30 \%$. Las sales biliares son necesarias para facilitar su absorción, la cual ocurre durante 30 minutos, con un pico plasmático de 2 a 4 horas y una vida media de 18 horas. El 80 \% de la dosis se une a lipoproteínas y se acumula en los tejidos adiposos, con una pobre penetración al sistema nervioso central. Es metabolizada por el citocromo $\mathrm{P} 4503 \mathrm{~A} 4$ y 3 A5, por lo que tiene numerosas interacciones medicamentosas. La ciclosporina tiene una recirculación entero-hepática, y se elimina principalmente en la bilis y las heces.

La presentación comercial es en cápsulas de 25, 500100 $\mathrm{mg}$, y la dosis inicial recomendada es de $2,5 \mathrm{mg} / \mathrm{kg}$ por día en una o dos tomas. En caso de no observarse mejoría en 2 a 4 semanas, se puede aumentar la dosis diaria de 0,5 a $1 \mathrm{mg} / \mathrm{kg}$ cada dos semanas, hasta un máximo de $5 \mathrm{mg} / \mathrm{kg} /$ día $^{2,5,26}$.

La ciclosporina se usa idealmente como tratamiento de urgencia en caso de una crisis ocasional o cuando hay resistencia a los corticoides, por periodos cortos de tres a cuatro meses, en lugar de administrarla a largo plazo, principalmente en psoriasis grave y dermatitis atópica. Sus contraindicaciones son infección grave, hipertensión arterial sistémica no controlada o insuficiencia renal. Ocasiona numerosos efectos secundarios, lo que limita muchas veces su uso, como insuficiencia renal, hipertensión arterial sistémica, colestasis transitoria, hiperuricemia, hipertricosis lanuginosa, hipertrofia gingival, trastornos gastrointestinales y, con menor frecuencia, citopenias, pancreatitis, encefalopatías, manifestaciones neuromusculares (parestesias, temblores, calambres) y aumento del riesgo de carcinomas cutáneos, con un riesgo relativo de $2,1^{1,2,26,28}$.

\section{CICLOFOSFAMIDA}

La ciclofosfamida pertenece a la familia de las mostazas nitrogenadas, con potentes efectos citotóxicos e inmunosupresores. Es ampliamente usada en otras especialidades diferentes a la dermatología, para tratar neoplasias malignas y manifestaciones graves de enfermedades autoinmunitarias como en el lupus, las vasculitis y la esclerosis sistémica. Su acción consiste en inhibir la replicación del ADN y actuar sobre los linfocitos B y T, especialmente sobre las células B, y la inmunidad humoral ${ }^{1,29}$.

Este medicamento es un profármaco inactivo, el cual se hidroxila en el hígado en 4-hidroxi-ciclofosfamida y en aldociclofosfamida, y, posteriormente, en mostaza fosforamida (metabolito activo) y acroleína (metabolito urotóxico). Los metabolitos activos tienen acciones alquilantes independientemente del ciclo celular, lo que resulta en un entrecruzamiento con las hebras de ADN, inhibiendo así su replicación. Su mecanismo específico no es bien comprendido, pero se sabe que induce apoptosis, disminuye la producción de inmunoglobulinas debido a la supresión de linfocitos B, y reduce la elaboración de moléculas de adhesión y citocinas ${ }^{1,29}$.

La ciclofosfamida se absorbe bien por vía oral y alcanza su pico de concentración plasmática en tres horas; su vida media es de 5 a 6 horas. No se une significativamente a las proteínas plasmáticas, se metaboliza en el hígado por la citocromo $\mathrm{P} 450$ y se elimina por el riñón. Se usa como tratamiento de enfermedades graves, no controladas; sus principales indicaciones en dermatología son las enfermedades ampollosas autoinmunitarias, las vasculitis, las enfermedades del tejido conjuntivo, los linfomas cutáneos de células $\mathrm{T}$ y las dermatosis neutrofílicas. La dosis oral diaria es de 1 a $3 \mathrm{mg} / \mathrm{kg}$ (50 a $200 \mathrm{mg} /$ día) o pulsos mensuales de 10 a $15 \mathrm{mg} / \mathrm{kg}^{1,2,6,29}$. No se recomienda su prescripción a largo plazo por su riesgo urológico y carcinogénico, principalmente tumores uroteliales. Dicha toxicidad urinaria se manifiesta con cistitis hemorrágica, necrosis y fibrosis vesical. Entre los efectos secundarios más frecuentes, se encuentran la mielosupresión y las manifestaciones digestivas como náuseas y vómito. Está contraindicado en casos de infección urinaria recurrente, cistitis hemorrágica, insuficiencia medular, o embarazo y lactancia ${ }^{1,5,30}$. En la tabla 4 se indican los usos dermatológicos de los inmunosupresores no biológicos y en la tabla 5 se resume el seguimiento clínico durante su administración.

\section{RECOMENDACIONES DE INMUNIZACIÓN Y PROFILAXIS}

La mayoría de los inmunosupresores no biológicos causan algún grado de compromiso inmunológico y pueden asociarse con la reactivación de enfermedades infecciosas como estrongiloidiasis, herpes zóster, tuberculosis, hepatitis B (HBV) y hepatitis C (HCV), además de complicaciones en pacientes portadores del virus de la inmunodeficiencia humana (HIV) ${ }^{31,32}$.

El dermatólogo debe evaluar los factores de riesgo en cada paciente y considerar realizar una tamización para estas enfermedades (tabla 6). Según los resultados, debe familiarizarse con las vacunas y los medicamentos empleados para su profilaxis. 


\begin{tabular}{|c|c|c|}
\hline \multicolumn{3}{|c|}{ CONTROL DEL USO DE INMUNOSUPRESORES NO BIOLÓGICOS } \\
\hline MEDICAMENTO & ¿QUÉ CONTROLAR? & FRECUENCIA \\
\hline \multirow{5}{*}{ Corticoesteroides 8,9} & IMC, presión arterial & En cada control \\
\hline & Glicemia, HbA1c & c/3-6 meses x 1er año, luego c/año \\
\hline & Perfil lipídico & al mes de iniciar, luego $c / 6-12$ meses \\
\hline & DMO (DEXA) & c/año \\
\hline & Examen oftalmológico & c/año \\
\hline \multirow{5}{*}{ Metrotexate $_{12}$} & Hemograma & c/3-4 meses \\
\hline & Función renal & c/3-4 meses \\
\hline & Función hepática & c/3-4 meses \\
\hline & Biopsia hepática & $\begin{array}{l}\text { Considerar al inicio si antecedente de enfermedad } \\
\text { hepática significativa, o durante tratamiento si } \\
\text { presenta anormalidades y el hepatólogo } \\
\text { lo recomienda. }\end{array}$ \\
\hline & Prueba de embarazo & al inicio (anticoncepción) \\
\hline \multirow{4}{*}{ Azatioprina $_{17}$} & Hemograma & c/2-3 meses \\
\hline & Función hepática & c/2-3 meses \\
\hline & Función renal & al inicio \\
\hline & Prueba de embarazo & al inicio \\
\hline \multirow{4}{*}{$\begin{array}{l}\text { Micofenolato de } \\
\text { mofetilo }_{20}\end{array}$} & Hemograma & c/mes \\
\hline & Función hepática & $\mathrm{c} / \mathrm{mes}$ \\
\hline & Función renal & $\mathrm{c} / \mathrm{mes}$ \\
\hline & Prueba de embarazo & al inicio \\
\hline \multirow{3}{*}{ Antipalúdicos 22} & Hemograma & al inicio, $c / 4-6$ meses \\
\hline & Función hepática & al inicio, $c / 4-6$ meses \\
\hline & Examen oftalmológico & al inicio, c/año \\
\hline \multirow{7}{*}{ Ciclosporina $_{25,28}$} & Hemograma & c/2-3 meses \\
\hline & Función renal & $\mathrm{c} / \mathrm{mes}$ \\
\hline & Función hepática & c/2-3 meses \\
\hline & Electrolitos $(\mathrm{Mg}, \mathrm{K})$ & al inicio \\
\hline & Ácido úrico & al inicio \\
\hline & Prueba de embarazo & al inicio \\
\hline & Presión arterial & $\mathrm{c} / \mathrm{mes}$ \\
\hline \multirow{4}{*}{ Ciclofosfamida 29} & Hemograma & c/1-3 meses \\
\hline & Función renal & $\mathrm{c} / 3$ meses \\
\hline & Función hepática & c/3 meses \\
\hline & Uroanálisis & $\mathrm{c} / 3$ meses \\
\hline
\end{tabular}

Tabla 5. Control del uso de inmunosupresores no biológicos. Para metotrexato, azatioprina, ciclosporina, micofenolato y ciclofosfamida, se recomienda control de hemograma y pruebas hepáticas en las primeras dos semanas de administración y repetir según resultados

Además, es necesario tener en cuenta el esquema de inmunización requerido por los pacientes que vayan a someterse a inmunosupresión por medicamentos (tabla 7).

\section{CONCLUSIONES}

Con la anterior revisión de tema se busca orientar al dermatólogo sobre aspectos que debe tener en cuenta en 


\section{TAMIZACIÓN SEGÚN LA ENFERMEDAD INFECCIOSA}

Infección

Examen
Estrongiloidiasis No requiere examen; hacer tratamiento con ivermectina oral ${ }_{34}$.
Tuberculosis Radiografía de tórax, prueba de tuberculina (PPD), baciloscopia seriada de esputo cuando la PPD sea positiva ${ }_{35}$

Hepatitis B Antígeno de superficie de hepatitis B, anticuerpos contra el antígeno de superficie de hepatitis B, anti core-total de hepatitis B Correlacionar los resultados para establecer la infección ${ }_{36,37.38}$

Hepatitis C Anticuerpos contra el virus de la hepatitis $C_{39}$

HIV ELISA para $\mathrm{HIV}_{40}$

Tabla 6. Tamización según la enfermedad infecciosa

\begin{tabular}{|c|c|}
\hline Vacuna & $\begin{array}{l}\text { QUEMA DE VACUNACIÓN RECOMENDADO } \\
\qquad \text { Periodicidad }\end{array}$ \\
\hline $\begin{array}{l}\text { Virus de la influenza } \\
\text { estacional }\end{array}$ & Anual \\
\hline Varicela zóster & Dosis única en pacientes de 60 años en adelante ${ }_{41,42}$ \\
\hline Neumococo & Cada 5 años \\
\hline Hepatitis B & $\begin{array}{l}\text { Aplicar en caso de no presentar anticuerpos contra el virus; } \\
\text { esquema: } 0-2-6 \text { meses }\end{array}$ \\
\hline
\end{tabular}

Tabla 7. Esquema de vacunación recomendado

Fuente: Centers for Disease Control and Prevention

la formulación de la terapia inmunosupresora no biológica. Es necesario recordar el mecanismo de acción, la posología, las indicaciones y el seguimiento durante el tratamiento, además de medidas profilácticas como la administración de ivermectina oral y la vacunación contra el virus de la influenza estacional, la varicela zóster, el neumococo y la hepatitis $B$, que serán de utilidad en el ejercicio de la profesión y contribuirán a un tratamiento farmacológico más seguro para los pacientes.

\section{REFERENCIAS}

1. Meyer N, Viraben R, Paul C. Inmunosupresores sistémicos en dermatología. EMC-Dermatología. 2008:42:1-15.

2. Stern DK, Tripp JM, Ho VC, Lebwohl M. The use of systemic immune moderators in dermatology. Dermatol Clin. 2005;23:259-300.

3. Hassan I, Aleem S, Sheikh G, Anwar P. Biologics in dermatology: A brief review. BJMP. 2013;6:62937. 
4. Rosman Z, Shoenfeld Y, Zandman-Goddard G. Biologic therapy for autoimmune diseases: An update. BMC Medicine. 2013;11:1-12.

5. Dutz J, Ho V. Immunosuppressive agents in skin disorders. Clin Immunother. 1996;5:268-93.

6. Dutz JP, Ho VC. Immunosuppressive agents in dermatology: An update. Dermatol Clin. 1998;16:235-51.

7. Jackson S, Gilchrist H, Nesbitt LT. Update on the dermatologic use of systemic glucocorticosteroids. Dermatol Ther. 2007;20:187-205.

8. Williams LC, Nesbitt LT. Update on systemic glucocorticosteroids in dermatology. Dermatol Clin. 2001;19:63-77.

9. Liu D, Ahmet A, Ward L, Krishnamoorthy P, Mandelcorn ED, Leigh R, et al. A practical guide to the monitoring and management of the complications of systemic corticosteroid therapy. Allergy Asthma Clin Immunol. 2013;9:1-25.

10. Banger CA, Costner MI. Methotrexate in dermatology. Dermatol Ther. 2007;20:216-228.

11. Shen S, O’Brien T, Yap LM, Prince HM, McCormack CJ. The use of methotrexate in dermatology: A review. Australas J Dermatol. 2012;53:118.

12. Barker J, Horn EJ, Lebwohl M, Warren RB, Nast A, Rosenberg W, et al. Assessment and management of methotrexate hepatotoxicity in psoriasis patients: Report from a consensus conference to evaluate current practice and identify key questions toward optimizing methotrexate use in the clinic. J Eur Acad Dermatol Venereol. 2011;25:758-64.

13. Meggitt SJ, Anstey AV, Mohd Mustapa MF, Reynolds NJ, Wakelin S. British Association of Dermatologists' guidelines for the safe and effective prescribing of azathioprine 2011. Br J Dermatol. 2011;165:711-34.

14. Wise M, Callen JP. Azathioprine: A guide for the management of dermatology patients. Dermatol Ther. 2007;20:206-15.

15. Polifka JE, Friedman JM. Teratogen update: Azathioprine and 6-mercaptopurine. Teratology. 2002;65:240-61.

16. El-Azhary RA. Azathioprine: Current status and future considerations. Int J Dermatol. 2003;42:335-41.

17. Anstey AV, Wakelin S, Reynolds NJ. Guidelines for prescribing azathioprine in dermatology. $\mathrm{Br}$ J Dermatol. 2004;151:1123-32.

18. Zwerner J, Fiorentino D. Mycophenolatemofetil. Dermatol Ther. 2007;20:229-38.
19. Orvis AK, Wesson SK, Breza TS, Church AA, Mitchell CL, Watkins SW. Mycophenolate mofetil in dermatology. J Am Acad Dermatol. 2009;60:18399.

20. Li J, Chong AH, Green J, Kelly R, Baker C. Mycophenolate use in dermatology: A clinical audit. Australas J Dermatol. 2013;54:296-302.

21. Kalia S, Dutz JP. New concepts in antimalarial use and mode of action in dermatology. Dermatol Ther. 2007;20:160-74.

22. Rodríguez-Caruncho C, Bielsa-Marsol I. Antipalúdicos en dermatología: mecanismo de acción, indicaciones y efectos secundarios. Actas Dermosifiliogr. 2014;105:243-52.

23. van Beek MJ, Piette WW. Antimalarials. Dermatol Ther. 2001;14:143-53.

24. González-Sixto B, García-Doval I, Oliveira R, Posada C, García-Cruz MA, Cruces M. Aspectos prácticos de la quinacrina como tratamiento del lupus eritematoso cutáneo: serie de casos. Actas Dermosifiliogr. 2010;101:54-8.

25. Amor KT, Ryan C, Menter A. The use of cyclosporine in dermatology: Part I. J Am Acad Dermatol. 2010;63:925-46.

26. Amor KT, Ryan C, Menter A. The use of cyclosporine in dermatology: Part II. J Am Acad Dermatol. 2010;63:949-72.

27. Colombo D, Poggi S. Clinical profile of cyclosporine in dermatology. Drug Dev Res. 2011;72:63446.

28. Cather JC, Abramovits W, Menter A. Cyclosporine and tacrolimus in dermatology. Dermatol Clin. 2001;19:119-37.

29. Kim J, Chan JJ. Cyclophosphamide in dermatology. Australas J Dermatol. 2016;50:1-13.

30. Ghate J. Immunosupressive therapies in dermatology: Cyclophosphamide. Curr Probl Dermatol. 2000;11:265-6.

31. Goyal A, Goyal K, Merola JF. Screening and vaccinations in patients requiring systemic immunosuppression: An update for dermatologists. Am J Clin Dermatol. 2015;16:179-95.

32. Keith P, Wetter D, Wilson J. Evidence-based guidelines for laboratory screening for infectious diseases before initiation of systemic immunosuppressive agents in patients with autoinmune bullous dermatoses. Br J Dermatol. 2014;171:1307-17.

33. Siddiqui AA, Berk SL. Diagnosis of Strongyloides stercoralis infection. Clin Infect Dis. 2001;33:1040-7.

34. American Thoracic Society. Targeted tuberculin 
testing and treatment of latent tuberculosis infection. MMWR Recomm Rep. 2000;49:1-51.

35. Weinbaum CM, Williams I, Mast EE, Wang SA, Finelli L, Wasley A, et al. Recommendations for identification and public health management of persons with chronic hepatitis B virus infection. MMWR Recomm Rep. 2008;57:1-20.

36. Hoofnagle JH. Reactivation of hepatitis B. Hepatology. 2009;49:156-65.

37. Ito S, Nakazono K, Murasawa A, Mita Y, Hata K, Saito N, et al. Development of fulminant hepatitis B (precore variant mutant type) after the discontinuation of low-dose methotrexate therapy in a rheumatoid arthritis patient. Arthritis Rheum. 2001;44:339-42.

38. Alter MJ, Kuhnert WL, Finelli L. Guidelines for laboratory testing and result reporting of antibody to hepatitis C virus. MMWR Recomm Rep. 2003;52:1-13.

39. Şanlıdağ T, Akçalı S, Ecemiş T. Investigation of the correlation between anti-HCV levels (S/ Co) with HCV-RNA in the diagnosis of hepatitis $\mathrm{C}$ virus (HCV) infection. Mikrobiyol Bul. 2016;50:508-10.

40. Roberts K, Macleod J, Metcalfe C. Hepatitis C - Assessment to Treatment Trial (HepCATT) in primary care: Study protocol for a cluster randomized controlled trial. Trials. 2016;17:366.

41. Moyer VA; US Preventive Services Task Force. Screening for HIV: US Preventive Services Task Force recommendation statement. Ann Intern Med. 2013;159:51-60.

42. Barin F, Meyer L, Lancar R. Development and validation of an immunoassay for identification of recent human immunodeficiency virus type 1 infections and its use on dried serum spots. J Clin Microbiol. 2005;43:4441-7.

43. Prazuck T, Karon S, Gubavu C. A finger-stick whole-blood HIV self-test as an HIV screening tool adapted to the general public. PLoS One. 2016;11:1-10.

44. Sitaras I, Rousou X, Kalthoff D. Role of vaccination-induced immunity and antigenic distance in the transmission dynamics of highly pathogenic avian influenza $\mathrm{H}_{5} \mathrm{~N} 1$. J R Soc Interface. 2016;13:1-15.

45. Centers for Disease Control and Prevention. Shingles (Herpes Zoster) vaccination. Fecha de consulta: 20 de mayo de 2016. Disponible en: http://www.cdc.gov/vaccines/vpd-vac/shingles/]

46. Harpaz R, Ortega-Sánchez IR, Seward JF. Pre- vention of herpes zoster: Recommendations of the Advisory Committee on Immunization Practices (ACIP). MMWR Recomm Rep. 2008;57:1-30.

47. Albrich W. Pneumococcal vaccination for children and adults. Ther Umsch. 2016;73:235-40.

48. Chakravarthi PS, Ganta A, Kattimani VS. Adult immunization -Need of the hour. J Int Soc Prev Community Dent. 2016;6:272-7.

49. Centers for Disease Control and Prevention (CDC). Impact of vaccines universally recommended for children - United States, 1990-1998. MMWR Morb Mortal Wkly Rep. 1999;48:243-8. 